\title{
BRIEF
}

\section{Student Performance With Graded vs. Ungraded Readiness Assurance Tests in a Team- Based Learning Elective}

\author{
Sarah T. Eudaley, PharmD, ${ }^{a}$ Michelle Z. Farland, PharmD, b Tyler Melton, PharmD, MPH, ${ }^{a}$ Shelby P. Brooks, \\ PharmD, ${ }^{c}$ R. Eric Heidel, PhD, ${ }^{d}$ Andrea S. Franks, PharmD ${ }^{\text {a }}$ \\ ${ }^{\text {a }}$ University of Tennessee Health Science Center, College of Pharmacy, Knoxville, Tennessee \\ ${ }^{\mathrm{b}}$ University of Florida, College of Pharmacy, Gainesville, Florida \\ ${ }^{\mathrm{c}}$ University of Louisiana at Monroe, College of Pharmacy - Shreveport Campus, Shreveport, Louisiana \\ ${ }^{\mathrm{d}}$ University of Tennessee, Graduate School of Medicine, Knoxville, Tennessee
}

Corresponding Author: Sarah T. Eudaley, University of Tennessee Health Science Center, College of Pharmacy, 1924 Alcoa Hwy, Box 117, Knoxville, TN 37920. Tel: 865-946-3412. Email: seudaley@uthsc.edu

Submitted August 16, 2021; accepted January 4, 2022; ePublished January 2022

Objective. Team-based Learning (TBL) is widely used in pharmacy education. There is debate regarding the necessity of graded readiness assurance tests (RATs) as incentive to complete pre-class preparation. The purpose of this study was to determine the effect of graded vs ungraded RATs on exam performance in an Ambulatory Care elective course for third year student pharmacists.

Methods. For the course offered in Spring 2020 and 2021, standard TBL framework was employed. RATs were graded in 2020 (graded RAT cohort), but did not contribute to overall course grade in 2021 (ungraded RAT cohort). An online anonymous survey of students determining class preparation and perceived team accountability was administered at course completion in the ungraded RAT cohort.

Results. There was no significant difference between the graded RAT $(n=47)$ and ungraded RAT cohorts $(n=36)$ in overall mean percentage score on individual RATs (76\% vs 74\%) and individual exams (82 vs 80\%). Most students (69$91 \%$ ) in the ungraded RAT cohort reported completing pre-class preparation assignments. Ninety-four percent agreed or strongly agreed they contributed to team members' learning and $86 \%$ agreed or strongly agreed they were proud of their ability to assist in the team's learning.

Conclusion. Ungraded RATs did not significantly impact student exam performance in an elective course. Removal of this assessment that promotes the performance-approach to learning may have contributed to a shift in motivation to the mastery-approach in the context of pre-class preparation. This challenges a widely held belief that grades are necessary incentives for pre-class preparation within TBL.

Keywords: team-based learning, pharmacy education, readiness-assurance test, assessment 


\section{INTRODUCTION}

Team-based learning (TBL), a student-centered, collaborative, active learning strategy, is widely used in pharmacy education. ${ }^{1}$ Literature characterizing TBL in pharmacy education describes student performance, critical thinking, problem solving, and engagement as well as faculty and student perceptions..$^{2-9}$ The standard framework for TBL includes individual pre-class preparation, readiness assurance tests (RATs), team application exercises, content-expert facilitated inter-team discussion, and peer evaluation. RATs consist of multiple-choice items developed to ensure foundational knowledge and preparation to engage in higher-level discussions during team application exercises. The individual RAT (iRAT) assures individual student preparation, while the team RAT (tRAT) allows peer-to-peer teaching through clarification of concepts from preparation materials by discussing the RAT. Within the standard TBL framework, RATs contribute to the overall course grade and incentivize students to prepare for class. ${ }^{10-12}$

Synchronous online course delivery, a necessity for the 2020-2021 academic year, created a new learning environment. While continued use of TBL maintained a community atmosphere with active engagement, it was not feasible to proctor formative assessments. Since RATs are delivered in a multiple-choice format and focus on foundational knowledge, this contributes to potential academic dishonesty, negating the learning power of the readiness assurance process. ${ }^{13}$ One approach to mitigate academic dishonesty is to remove the motivation to engage in these behaviors and not have scores contribute to the course grade..$^{14-15}$

There is limited evidence on ungraded readiness assurance processes within TBL. Student accountability for preclass preparation is paramount for successful student learning and is determined by utilizing iRATs. ${ }^{10}$ Some educators posit that an incentive structure (eg, graded activity) must be in place as an extrinsic motivator to encourage students to complete pre-class preparation. ${ }^{11,12}$ Others contend graded formative assessments, like RATs, cause undue student stress and facilitate superficial learning to perform on the assessment. ${ }^{14}$ Graded assessments as incentives may motivate learners to use the performance-approach to learning with a goal only to perform on the assessment. ${ }^{16}$ This may also promote performance-avoidance learning, through which students engage with material to seek approval from others and to appear competent. ${ }^{16}$ Both performance-approach and performance-avoidance lead the learner to focus on the assessment rather than mastery of material, which is crucial for practicing pharmacists. ${ }^{17}$ In the absence of graded formative assessments, the stress and anxiety caused by the pressure to perform is removed and students can engage in deeper learning and mastery of material. ${ }^{16}$ Students with a mastery-approach to learning are intrinsically motivated, with the goal to improve their own knowledge and competencies, rather than to perform on an assessment. ${ }^{16}$ In the absence of graded formative assessments, additional extrinsic motivators for individual class preparedness may still exist through exam performance and team accountability. ${ }^{12}$ This study was designed to contribute additional information to the debate regarding incentive structures for learning in TBL classrooms. The purpose was to determine the effect of graded vs ungraded RATs (formative assessments) on exam performance (summative assessments) in an elective course.

\section{METHODS}

\section{Course Description}

The Ambulatory Care elective is a 2-credit hour course for third professional year PharmD students at the University of Tennessee Health Science Center College of Pharmacy. The 2020 course offering included three 2-hour class sessions weekly over six weeks with each session covering one of eleven topics. The standard TBL framework was employed, except for peer evaluation. TBL was used to deliver course material synchronously across three campuses using videoconferencing. For each class session, one content expert facilitated from one of three campuses. Teams consisted of students from the same campus who met in person for class and were developed using random numbers generator. There were 11 RATs (10-multiple choice items per RAT) and two exams (25-multiple choice items). iRATs were completed using Examplify (Examsoft Worldwide, Inc). tRATs were completed using Immediate Feedback Assessment Technique (IF-AT) (Epstein Educational Enterprises, Inc) cards, which use an answer-until-correct method and partial credit. ${ }^{18}$ Individual and team exams were completed using Examplify (Examsoft Worldwide, Inc). Proctors for RATs and exams were present in the classroom on each campus.

The 2021 course offering was delivered using TBL within the same time-frame, but through synchronous videoconferencing using Zoom (Zoom Video Communications, Inc). The same 11 topics in identical sequence to the 2020 offering were included. Teams consisted of students from different campuses. All students interacted synchronously online with faculty content experts, team members, and classmates. iRATs were completed using the online learning management system (Blackboard Inc.) and tRATs were completed using Microsoft Forms (Microsoft), without the answer-until-correct method. Individual and team exams were completed using Examplify (Examsoft Worldwide, Inc) and Microsoft Forms (Microsoft), respectively. Topics on each exam were the same as the 2020 course offering. Exams were proctored by faculty/staff through Zoom (Zoom Video Communications, Inc) using methods developed at our college. ${ }^{19}$ 
Students were divided into three groups for the individual exam and received a Zoom link from the individual proctor. Student identification was verified upon entry into the Zoom (Zoom Video Communications, Inc) meeting and surroundings were viewed by the proctor. Once individual exams were all complete, students were assigned to team breakout rooms to complete the team exam. The assigned proctor entered and exited assigned rooms during team exam completion.

For the 2021 ungraded RAT cohort, intense proctoring of RATs for individual students was not feasible. Because of the value of RATs within TBL pedagogy, RATs were included within the course, however the incentive grading structure was different. For the ungraded RAT cohort, the iRAT and tRAT accounted for $2.5 \%$ of the final course grade and were for participation only, in contrast to the graded RAT cohort, for which iRAT and tRAT grades accounted for $20 \%$ and $30 \%$ of the final course grade, respectively (Table 1).

\section{Data Analysis}

The institutional review board granted approval for this study. Cohort demographics were compared using the student's $t$-test and chi square, as appropriate. Exam grades, individual mean percentage scores for iRATs, and Pharmacotherapy Integrated Modules Grade Point Average (PIM-GPA) were compared using the student's $t$-test. PIMGPA was calculated from grades earned in PIMs completed prior to enrollment in the elective. Individual mean percentage score for iRATs was calculated by adding iRAT scores, then dividing by the total number of TBL sessions for which the student completed an iRAT to account for potential absences leading to a difference in the number of TBL sessions.

At course conclusion the ungraded RAT cohort completed an anonymous survey (QuestionPro Inc.). The survey included three demographic items, three items adapted from a previously published survey to determine class preparation, and the accountability subscale of the Team-Based Learning Student Assessment Instrument (TBL-SAI). ${ }^{20,21}$ The accountability subscale included eight items for students to rate level of agreement with a 5-point Likert scale ranging from strongly disagree (1) to strongly agree (5). Survey response frequencies were summarized using descriptive statistics.

\section{RESULTS}

Forty-seven and 36 students enrolled in the graded RAT (2020) and ungraded RAT (2021) cohorts, respectively. No significant differences existed in student characteristics between cohorts with regard to mean age in years (graded RAT: $26(S D=3)$ vs ungraded RAT: $26(S D=2) ; p=.68)$, percentage female students (62\% vs $\left.57 \% ; x^{2}=0.17, p=.57\right)$, student-reported prior TBL participation ( $70 \%$ vs $74 \% ; x^{2}=.04, p=.84$ ), or mean PIM-GPA (2.9 (SD=0.6) vs $3(S D=0.7)$; $p=.31$ ). There was no statistical difference in overall mean iRAT or individual exam scores (Table 2).

Ninety-seven percent $(n=35)$ of the ungraded RAT cohort completed the survey. Student responses to the accountability subscale of the TBL-SAI are in Table 3. Most students $(51 \%, n=18)$ spent an average of one to two hours preparing for each session, followed by $31 \%(n=11)$ who reported spending an average of 30-60 minutes. For each session, 69-91\% of students reported preparing for class, although one student reported not preparing for any sessions. Reasons for not preparing included too much material (20.8\%), felt prepared for class without completing the required readings $(15 \%)$, class preparation took too much time $(10 \%)$, no incentive to participate since iRATs were not graded $(0 \%)$.

\section{DISCUSSION}

TBL incorporates multiple levels of student accountability. First, students are individually accountable to perform well on the iRAT. Second, students are accountable to their team members to perform well on the tRAT and team application exercises. Our investigation of adjusting the incentive structure in a TBL classroom using graded or ungraded RATs demonstrated no significant difference in performance on individual overall formative and summative assessments. This important finding is contrary to the widely held belief that a graded incentive structure is needed to extrinsically motivate students to complete pre-class preparation. These results confirm previously published data by Koh and colleagues that demonstrated a slight decline in formative assessment performance, but sustained performance on summative assessments..$^{22}$ Our results, along with previously published data, challenge one of the core beliefs in TBL, that graded iRATs incentivize and extrinsically motivate students' individual class preparation. ${ }^{11}$

Foundational knowledge established through pre-class preparation is crucial within TBL for ensuring proper peerto-peer learning, supporting team answers, and achieving consensus during team application exercises. While some degree of extrinsic motivation still exists in this structure (eg, accountability to the team and graded exams), this process does not appear to require a graded formative assessment to remain effective. Participating in an iRAT (graded or ungraded) engages retrieval practice that solidifies knowledge and brings awareness to knowledge gaps. Perhaps removal of the 
graded formative assessments allowed students to shift learning motivation from performance-approach and/or performance-avoidance to the learning-approach, allowing students to focus on mastery of material rather than performance on assessments. Mastery of material may have been indirectly attributed to performance on other graded assessments within the course. Accountability to a team of peers may also motivate students to prepare for class, as the TBL structure emphasizes peer-to-peer learning during the tRAT and team application exercises. Results from the end-ofcourse survey of the ungraded RAT cohort confirmed students felt a responsibility to team members (Table 3). Most reported feeling a need to contribute to the team, and perceived their contributions as important, indicating perceived benefit from team interactions that enhanced learning. Regarding class preparation, most students agreed or strongly agreed class preparation was necessary to do well in the course (Table 3). Most students completed preparation assignments, though it varied by topic and reasons for not preparing. Notably, none of the students reported RATs not contributing to the course grade as a reason for lack of pre-class preparation. This may demonstrate that although ungraded RATs did not serve as an incentive for class preparation, students viewed team accountability as an extrinsic motivator, enticing them to maintain engagement with course material despite the lack of a peer evaluation process. Within this incentive structure, individual exam performance may have also been perceived as an extrinsic motivator. Although there was no difference in overall scores for formative and summative assessments, it is important to note a statistical difference in scores between cohorts for exam 1 iRATs and individual exam 1, with the ungraded RAT cohort scoring 5\% and 7\% lower, respectively (Table 2). Although approximately $70 \%$ of students from both cohorts reported prior participation in TBL, delivery can vary significantly between courses. As well, the ungraded RAT cohort was adjusting to TBL delivery using live synchronous video conferencing rather than in-person TBL delivered synchronously across three campuses. This adjustment may have contributed to differences in scores on exam $1 \mathrm{iRATs}$ and individual exam 1. For exam two, perhaps students adjusted to this environment, leading to better assessment performance. This adjustment may not have been observed for the graded RAT cohort since the iRATs were graded and IF-AT cards were used for tRATs, facilitating more initial engagement with material earlier on during the course.

There are some limitations of this study that must be considered. This was an elective course, so students may have been more engaged in subject matter and therefore intrinsically motivated to prepare for and engage in class compared to a required course. Interest in the course content may have increased the likelihood for students to engage in the mastery-approach. Extrinsic motivators (eg, formative graded assessments, peer evaluations) may play a more crucial role in encouraging engagement with course content for a required course. While we did not collect download rates for pre-class materials as in previously published data, we attempted to characterize class preparation and perceptions through student survey responses for the ungraded RAT cohort, although we did not collect the same data for the graded cohort. Additionally, some content experts/facilitators differed between cohorts, although new facilitators received the same training for both cohorts. Individual facilitators identified pre-class preparation materials, wrote pre-class preparation objectives, created RAT questions, developed team-based application exercises, facilitated class discussion, and created exam questions.

\section{CONCLUSION}

Ungraded RATs did not significantly impact student performance on summative course assessments in an elective course. Ungraded formative assessments may have removed the pressure to learn in order to perform on an assessment and promoted learning to master material, allowing students to engage in the mastery-approach in this course. Students in the ungraded RAT cohort felt responsible to their team to prepare for class despite RATs not contributing to their course grade. We observed high rates of self-reported pre-class preparation and responsibility to contribute to team learning. Although the extrinsic motivator of graded RATs was removed, students may have viewed team accountability and exams as motivators to learn before and during class. This is supported by similar scores on overall formative and summative assessments between cohorts. Ungraded iRATs in TBL sessions for elective courses can be considered as an alternative approach to mitigate risk of academic dishonesty without fear of diminishing learning and student performance. 


\section{REFERENCES}

1. Allen RE, Copeland J, Franks AS, et al. Team-Based Learning (TBL) in US Colleges and Schools of Pharmacy. Am J Pharm Ed. 2013;77(6):Article 115.

2. Silberman D, Carpenter R, Takemoto, et al. The impact of team-based learning on the critical thinking skills of pharmacy students. Curr Pharm Teach Learn. 2021; 13:116-121.

3. Wheeler S, Valentino AS, Liston BW, et al. A team-based learning approach to interprofessional education of medical and pharmacy students. Curr Pharm Teach Learn. 2019; 11(11):1190-1195

4. Johnson JF, Bell E, Bottenberg, et al. A multiyear analysis of team-based learning in a pharmacotherapeutics course. Am J Pharm Educ. 2014; 78(7):Article 142.

5. Nelson M, Allison SD, McCollum M, et al. The Regis model for pharmacy education: a highly integrated curriculum delivered by team-based learning (TBL). Curr Pharm Teach Learn. 2013; 5(6):555-563.

6. Medina MS, Conway SE, Davis-Maxwell TS, Webb R. The impact of problem-solving feedback on team-based learning case responses. Am J Pharm Educ. 2013; 77(9): Article 189.

7. Kebodeauz CD, Peters GL, Stranges PM, et al. Faculty perceptions of team-based learning over multiple semesters. Curr Pharm Teach Learn. 2017; 9(6):1010-1015.

8. Zingone MM, Franks AS, Guirguis AB, et al. Comparing team-based learning and mixed active-learning methods in an ambulatory care elective. Am J Pharm Educ. 2010; 74(9):160.

9. Thompson BA, Schneider VF, Haidet P, Perkowski LC, Richards BF. Factors influencing implementation of team-based learning in health sciences education. Acad Med. 2007; 82(10 Suppl): S53-S56.

10. Michaelsen LK, Sweet M. Fundamental principles and practices of team-based learning. In Michaelsen LK, Parmelee DX, McMahon KK, Levin RE, eds. Team-Based Learning for Health Professions Education. Sterling, VA: Stylus; 2008:9-31.

11. Parmelee D, Michaelsen LK, Cook S, Hudes PD. Team-based learning: A practical guide: AMEE Guide No. 65, Med Teach. 2012; 34(5):e275-87.

12. Haidet P, Levine R, Parmelee DZ, et al. Guidelines for reporting team-based learning activities in the medical and health sciences education literature. Acad Med. 2012; 87(3): 292-299.

13. Ng HWW, Davies G, Bates I, Avellone A. Academic dishonesty among pharmacy students: investigating academic dishonesty behaviors in undergraduates. Pharm Educ. 2003; 3(4):261-9.

14. McLachlan, J. The relationship between assessment and learning. Med Educ. 2006; 40: 716-717.

15. Childs-Kean LM, Farland MZ. Stop tempting your students to cheat. Curr Pharm Teach Learn. 2021; 13:588-90.

16. Meece JL, Anderman EM, Anderman LH. Classroom goal structure, student motivation, and academic achievement. Annu. Rev. Psychol. 2006; 57: 487-503.

17. Medina MS, Plaza CM, Stowe CD, et al. Center for the Advancement of Pharmacy Education (CAPE) Educational Outcomes 2013. Am J Pharm Educ. 2013;77(8): Article 162.

18. Epstein Educational Enterprises. What is the IF-AT?. Accessed July 26, 2021. http://www.epsteineducation.com/home/about/.

19. Hall, EA, Spivey C, Kendrex H, Havrda. Efffects of remote proctoring on composite examination performance among doctor of pharmacy students. Am J Pharm Educ. 2021;85(8) Article 8410.

20. DeJongh B, Lemoine N, Buckley E, Traynor L. Student preparation time for traditional lecture vs TBL in PTx course. Curr Pharm Teach Learn. 2018; 10:360-366.

21. Mennenga HA. Development and psychometric testing of the team-based learning student assessment instrument. Nurse Educ. 2012; 37(4):168-172.

22. Koh JY, Rotgans JI, Rajalingam P, et al. Effects of graded versus ungraded individual readiness assurance scores in team-based learning: a quasi-experimental study. Adv Health Sci Educ. 2019; 24:477-488. 
Table 1. Course Grade Scheme

\begin{tabular}{lcc}
\hline & Graded RAT (\%) & $\begin{array}{c}\text { Ungraded } \\
\text { RAT (\%) }\end{array}$ \\
\hline iRAT & & $2.5^{*}$ \\
tRAT & 30 & $2.5^{*}$ \\
Midpoint Exam (individual) & 15 & 25 \\
Midpoint Exam (team) & 10 & 15 \\
Final Exam (individual) & 15 & 25 \\
Final Exam (team) & 10 & 15 \\
Exit Ticket & ----- & 15 \\
\hline
\end{tabular}

*submission of RATs for class participation (not individually graded); RAT=Readiness Assurance

Test; iRAT=Individual Readiness Assurance Test; tRAT=Team Readiness Assurance Test 
Table 2. Formative and Summative Assessment Grade Comparison Graded RAT Ungraded RAT $p$ value $(\mathbf{n}=\mathbf{4 7})$

iRAT (overall) iRAT Exam 1

iRAT Exam 2

$76(9.3)$

$79(10)$

$72(9)$

Individual Exam Grade (overall)

Exam 1

$82(8)$

$82(9)$

Exam 2

$83(9)$

(n=36)

iRAT = Individual Readiness Assurance Test

$74(7.8)$

74 (10)

$71(11)$

$80(9)$

$75(11)$

84 (10)

0.301
0.002
0.658
0.146
0.002
0.44

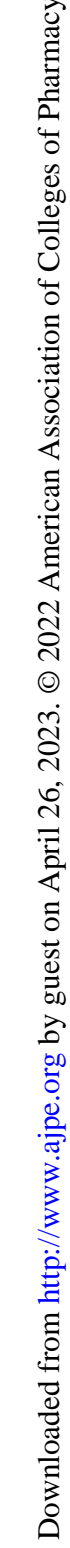


Table 3. Student Survey Responses in the Ungraded RAT cohort for the TBL-SAI Accountability

Subscale $^{18}(n=35)$

$\begin{array}{ccccc}\text { Strongly } & \text { Disagree } & \text { Neutral } & \text { Agree } & \text { Strongly } \\ \begin{array}{c}\text { Disagree } \\ (\%)\end{array} & (\%) & (\%) & (\%) & \text { Agree }(\%) \\ \end{array}$

\begin{tabular}{|c|c|c|c|c|c|}
\hline & & & & & \\
\hline $\begin{array}{l}\text { I spent time studying before class in order to be more } \\
\text { prepared. }\end{array}$ & 0 & 6 & 3 & 57 & 34 \\
\hline I felt I had to prepare for class in order to do well. & 0 & 0 & 9 & 42 & 49 \\
\hline I contributed to my team members' learning. & 0 & 0 & 6 & 43 & 51 \\
\hline My contribution to the team was not important. & 40 & 43 & 6 & 6 & 6 \\
\hline $\begin{array}{l}\text { My team members expected me to assist them in } \\
\text { their learning. }\end{array}$ & 0 & 3 & 46 & 34 & 17 \\
\hline I was accountable for my teams’ learning. & 3 & 3 & 32 & 46 & 17 \\
\hline $\begin{array}{l}\text { I was proud of my ability to assist my team in their } \\
\text { learning. }\end{array}$ & 0 & 3 & 11 & 54 & 31 \\
\hline $\begin{array}{l}\text { I needed to contribute to the team's learning. } \\
\text { *Percentages may not add up to } 100 \text { due to rounding } \\
\text { iRAT = Individual Readiness Assurance Test }\end{array}$ & 0 & 3 & 20 & 49 & 29 \\
\hline
\end{tabular}

